\title{
Mummy Berry Fruit Rot and Shoot Blight Incidence in Blueberry: Prediction, Ranking, and Stability in a Long-term Study
}

\author{
Mark K. Ehlenfeldt ${ }^{1,3}$, James J. Polashock ${ }^{1}$, and Allan W. Stretch ${ }^{2}$ \\ USDA-ARS, Genetic Improvement of Fruits and Vegetables Laboratory, \\ Henry A. Wallace Agricultural Research Center, Beltsville, MD 20705
}

\section{Matthew Kramer \\ USDA-ARS, Biometrical Consulting Service, Henry A. Wallace Agricultural Research Center, Beltsville, MD 20705}

Additional index words. modeling, environmental effects, weather, variance decomposition

\begin{abstract}
Mummy berry (Monilinia vaccinii-corymbosi) is an important disease of cultivated blueberry (Vaccinium spp.). The disease has two distinct phases: a blighting phase initiated by ascospores and a fruit infection stage initiated by conidia during bloom. In this study, we investigated, in a nursery setting, blueberry cultivar resistance to both phases of the disease and, using multiple "standards" with a range of susceptibilities, examined, over 9 to 12 years, factors affecting disease incidence in controlled inoculations. The analyses of our data show that a minimum of 8 years of testing is necessary to obtain stable rankings of cultivar susceptibility for the fruit infection phase of the disease. Insufficient years of data were available to estimate this for the blight phase. Eight years are necessary largely as a result of uncertainty arising from the large environment $\times$ genotype interaction, estimated to be more than double any other source of observed variation, other than that resulting from sampling/individual plants. For individual cultivars, temperature and the amount and frequency of precipitation in January to March (when neither plant nor pathogen were presumed active and when both were in cold frames somewhat protected from environmental conditions) were predictive of later disease incidence. For most cultivars, the same weather variables at the same time period were found to be predictive for independently modeled cultivars. Additional cultivars, with only a few years' data, were grouped with the standard with which they shared similar environmental (year) responses and possibly similar disease predictive models.
\end{abstract}

Mummy berry is one of the most important diseases of blueberry in North America (Eck and Childers, 1966). The disease affects all cultivated species, including highbush (Vaccinium corymbosum L.), lowbush ( $V$. angustifolium Aiton), and rabbiteye ( $V$. ashei Reade $=V$. virgatum Aiton) (Hildebrand et al., 1995). Wild species of blueberry such as $V$. myrtilloides Michaux and $V$. elliottii Chapman are also susceptible (Hildebrand et al., 1995). The disease is caused by the fungus Monilinia vaccinii-corymbosi (Reade) Honey. There are two distinct infection phases, each of which must be completed for the disease to persist. The primary phase results in blighting of shoots and sometimes flower clusters. This phase is initiated by germination of pseudosclerotia that form

Received for publication 27 Aug. 2009. Accepted for publication 16 Oct. 2009 .

${ }^{1}$ Mailing address: P.E. Marucci Center for Blueberry and Cranberry Research, 125A Lake Oswego Road, Chatsworth, NJ 08019.

${ }^{2}$ Retired.

${ }^{3}$ To whom reprint requests should be addressed; e-mail mark.ehlenfeldt@ars.usda.gov. highest at short shoot lengths (i.e., young shoots) and decreased as shoot length increased (more mature shoots). Among resistant cultivars, there were indications of resistance resulting from both avoidance (through delayed bud break) and biochemical or structural factors. Lehman and Oudemans (1997b) similarly demonstrated that susceptibility decreased as shoots elongated, suggesting the development of ontogenic resistance. Ehlenfeldt et al. (1996) evaluated cultivar differences in a 48-cultivar subset of those evaluated by Stretch et al. (1995) and found a significant positive correlation $(r=$ 0.74 ) between blight incidence and average shoot length during the first week of ascospore release. Fruit susceptibility in the mummy berry disease cycle was also investigated by Stretch and Ehlenfeldt (2000). No correlation was found between blight resistance and resistance to fruit infection $(r=0.15)$, but several cultivars appeared to offer good resistance to both phases. Biochemical or host resistance is thought to play a part in fruit infection resistance because growth of the fungus along the gynoecial pathway was shown to be slower in resistant cultivars (Lehman et al., 2007).

In this study, we compiled data from many years of screening blueberry cultivars for resistance to both phases of mummy berry disease. In developing resistance rankings, we found that even the cultivars included as standards varied in response from year to year and occasionally shifted ranks. To determine the number of years necessary for stable rankings, we decided to more fully analyze the response of the standards and better quantify the components of disease resistance beyond simply plant genotype. We applied variance decomposition methods to assess the contributions of: cultivar (genetic factors), year (weather and other environmental factors), and their interaction. As part of year and year $\times$ cultivar interaction, we investigated if weather variables such as temperature, rainfall, and humidity were useful predictors of disease incidence. The year $\times$ cultivar interaction is typically considered to be an "unpredictable" part of the cultivar $\times$ environment interaction (Lin and Binns, 1988). However, we found that weather variables from earlier in the year, in part, could explain year-to-year ranking shifts among cultivars. Thus, unique predictive equations for average disease incidence, based on weather variables and the cultivar's longterm mean resistance, may be derived for each cultivar.

\section{Materials and Methods}

1966). The most methodical screening for blight resistance (primary phase) was an evaluation of 52 highbush blueberry cultivars using concentrated inoculum in a nurserytype setting (Stretch et al., 1995) that identified several cultivars with good horticultural quality and high levels of resistance. In a later study, Ehlenfeldt et al. (1997) manipulated shoot elongation of resistant and susceptible cultivars to evaluate the nature of resistance. In susceptible cultivars, susceptibility was

\section{Blight screening materials}

Based on data from earlier screenings (Ehlenfeldt and Stretch, 2000; Stretch and Ehlenfeldt, 2000; Stretch et al., 1995), the following cultivars were selected as shoot blight standards to represent both highbush (HB) and rabbiteye (RE) genotypes and a broad range of responses from low to high. The cultivars that were included across 1996 
to 2007 were: 'Bluejay' (HB), 'Brightwell' (RE), 'Callaway' (RE), 'Coastal' (RE), 'Coville' (HB), 'Northblue' (HH, a half-high type, i.e., a lowbush $\times$ highbush hybrid), 'Sunrise' (HB), and 'Toro' (HB). 'Climax' (RE) was included from 1996 to 2006. An additional 36 cultivars were coscreened for 3 -year periods and analyzed against the shoot blight standards (Table 1).

\section{Fruit infection screening materials}

Similarly, six cultivars were selected as fruit infection standards based on data from earlier screenings (Stretch and Ehlenfeldt, 2000) and because they represented a range of responses from low to high. The cultivars that were included across 1995 to 2007 included: 'Atlantic' (HB), 'Bluejay' (HB), 'Blueray' (HB), 'Northsky' (HH), 'Rancocas' (HB), and 'Sierra' (HB). An additional 32 cultivars were coscreened for 3 -year periods and analyzed against the fruit infection standards (Table 2). Detailed background and pedigree information on the cultivars used in either screening test may be obtained by request from the authors. Additional information on some cultivars is available in the Germplasm Resources Information Network online database (GRIN; http://www.ars-grin. gov/npgs).

\section{Blight screening methods}

The tests were conducted outdoors in randomized complete block designs with five replicates (potted plants) per cultivar. Pots were arranged in a grid pattern in each replicate with the specific dimensions of the grid determined by the number of entries (cultivars) and the space allocated each year. The space between plants averaged $0.45 \mathrm{~m}$ and blocks were laid out linearly. The plants were potted in 2.84-L pots in a sand:peat mix (1:1). Plants for blight evaluation were typically 30 to $60 \mathrm{~cm}$ and were 5- to 6-year-old plants that had been cut back and allowed to regrow several times. The $M$. vacciniicorymbosi pseudosclerotia (mummies) used in each test were collected from the P.E. Marucci Center for Blueberry and Cranberry Research, Chatsworth, NJ. Pseudosclerotia were collected in September and October from the field, transplanted into soil-filled (1:1 sand:peat mix) $0.92-\mathrm{L}$ plastic pots, and overwintered in plastic-covered cold frames. At the start of each test (early April), pots containing pseudosclerotia with emerging apothecia were removed from the covered cold frames and placed at evenly spaced intervals within and around the periphery of the experiment area to provide an even distribution of inoculum. To enhance the infection process, the entire plot received supplemental misting for $1 \mathrm{~h}$ every evening during ascospore release (applied volume $\approx 5 \mathrm{~mm} / \mathrm{d}$ ).

Trials were typically initiated the first week of April with the timing determined by initiation of shoot development in the earliest emerging cultivars. Until the start of each test, the plants were sheltered in wellventilated, plastic-covered cold frames. Dur-

Table 1. Means and sDS of the blighted proportion (disease incidence) of shoots for cultivar standards and cultivars with a similar yearly disease incidence pattern.

\begin{tabular}{|c|c|c|}
\hline $\begin{array}{l}\text { Cultivar standards } \\
\text { for shoot blight }{ }^{2}\end{array}$ & $\begin{array}{c}\text { Blighted } \\
\text { proportion of } \\
\text { shoots-mean } \\
\text { and (SD) }\end{array}$ & Cultivars with similar yearly responses ${ }^{y}$ \\
\hline$\overline{\text { Bluejay }(\mathrm{HB})^{\mathrm{x}}}$ & $0.20(0.23)$ & $\begin{array}{l}\text { Bluebelle, Chanticleer, Clara, Cumberland, Echota, Pearl } \\
\text { River, Putte, Sampson, Scammell, Tifblue }\end{array}$ \\
\hline Toro (HB) & $0.22(0.24)$ & $\begin{array}{l}\text { Clara, Goldtraube, Jubilee, Olympia, O’Neal, Tifblue, } \\
\text { Wolcott }\end{array}$ \\
\hline Coastal (RE) & $0.36(0.27)$ & Bluebelle, Collins, Tifblue \\
\hline Callaway (RE) & $0.37(0.32)$ & $\begin{array}{l}\text { Ascorba, Bluegem, Bluebelle, Chandler, Clara, Cooper, } \\
\text { Olympia, Pender, Santa Fe, Wolcott }\end{array}$ \\
\hline Sunrise (HB) & $0.45(0.32)$ & $\begin{array}{l}\text { Ascorba, Bluegem, Briteblue, Chandler, Ethel, } \\
\text { Friendship, Misty, O’Neal, Ozarkblue, Pender, } \\
\text { Santa Fe, Tifblue }\end{array}$ \\
\hline Coville (HB) & $0.58(0.35)$ & $\begin{array}{l}\text { Black Giant, Denise Blue, Goldtraube, O’Neal, } \\
\text { Powderblue, Sunshine Blue }\end{array}$ \\
\hline Baldwin (RE) & $0.60(0.38)$ & $\begin{array}{l}\text { Clara, Friendship, Goldtraube, Misty, O’Neal, Putte, } \\
\text { Sampson, Suwanee, Tifblue }\end{array}$ \\
\hline Brightwell (RE) & $0.62(0.35)$ & $\begin{array}{l}\text { Clara, Collins, Denise Blue, Goldtraube, Premier, } \\
\text { Suwanee, Tifblue }\end{array}$ \\
\hline Northblue $(\mathrm{HH})$ & $0.77(0.24)$ & Concord, Jewel, Jubilee, Reka, Tifblue \\
\hline
\end{tabular}

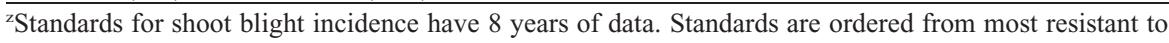
least resistant.

${ }^{y}$ Similarity does not imply similar levels of disease incidence, but rather a high correlation of response for years in common. Some of the standards were similar to each other, so cultivars may be similar to more than one standard.

${ }^{\times} \mathrm{RE}=$ rabbiteye; $\mathrm{HB}=$ highbush; $\mathrm{HH}=$ half-high.

Table 2. Means and sDs of the infected proportion (disease incidence) of berries for cultivar standards and cultivars with a similar yearly disease incidence pattern.

\begin{tabular}{|c|c|c|}
\hline $\begin{array}{l}\text { Cultivar standards for } \\
\text { fruit infection }\end{array}$ & $\begin{array}{c}\text { Infected } \\
\text { proportion of } \\
\text { berries-mean } \\
\text { and }(\mathrm{SD})\end{array}$ & Cultivars with similar yearly responses ${ }^{y}$ \\
\hline Northsky $(\mathrm{HH})^{\mathrm{x}}$ & $0.02(0.03)$ & \\
\hline Bluejay (HB) & $0.10(0.11)$ & $\begin{array}{l}\text { Collins, Croatan, Harrison, June, Morrow, } \\
\text { Murphy, Northblue, Windsor }\end{array}$ \\
\hline Rancocas (HB) & $0.22(0.22)$ & $\begin{array}{l}\text { Cabot, Cape Fear, Croatan, Friendship, Nelson, } \\
\text { Northblue, Ornablue, Polaris, Reka, Sunrise, } \\
\text { St. Cloud }\end{array}$ \\
\hline Blueray (HB) & $0.35(0.30)$ & Greta, Zuckertraube \\
\hline Sierra (HB) & $0.41(0.29)$ & $\begin{array}{l}\text { Bluetta, Blue Rose, Bonifacy, Echota, Gila, } \\
\text { Goldtraube, Northblue, Zuckertraube }\end{array}$ \\
\hline Atlantic (HB) & $0.53(0.26)$ & $\begin{array}{l}\text { Elizabeth, Elliott, Grover, Ivanhoe, Katherine, } \\
\text { Legacy, Wareham }\end{array}$ \\
\hline
\end{tabular}

${ }^{\mathrm{z}}$ Standards for fruit infection incidence have 11 to 12 years of data. Standards are ordered from most resistant to least resistant.

${ }^{y}$ Similarity does not imply similar levels of disease incidence, but rather a high correlation of response for years in common. Some of the standards were similar to each other, so cultivars may be similar to more than one standard.

${ }^{\mathrm{x}} \mathrm{HH}=$ half-high; $\mathrm{HB}=$ highbush.

ing the test, plants were examined for blighted shoots on a weekly basis between early May, when symptoms became visible, and late May/early June, when blighting was essentially complete. At each inspection, blighted shoots were tabulated and removed. At the end of the blight period, remaining healthy shoots were counted on each plant so that the percentage of blighted shoots could be calculated. Cultivars to be evaluated were included for 3 years and sometimes as many as 4 to 6 years if widely variable results were observed.

\section{Fruit infection screening methods}

The plants were maintained in $2.84-\mathrm{L}$ pots in a sand:peat $(1: 1)$ planting mix. The test was typically conducted in a cold frame covered with shadecloth ( $55 \%$ transmission) as a randomized complete block design of five replicates (potted plants) per cultivar. Plants for fruit infection evaluation were typically 50 to $80 \mathrm{~cm}$ and were also 5- to 6year-old plants that had been cut back and allowed to regrow several times. The space between plants averaged $0.45 \mathrm{~m}$ between rows and $0.36 \mathrm{~m}$ between plants within rows. In all years, blighted plants of 'Bluehaven' and 'Blueray' (also in 2.84-L pots) with sporulating blighted tissue were evenly distributed between every two rows of plants to serve as inoculum sources located within 0.5 $\mathrm{m}$ or less of the plants to be tested. In previous studies, 'Bluehaven' and 'Blueray' had averaged $63.9 \%$ and $35.6 \%$ blight, respectively, and had ranked as two of 47 and 11 of 47 with respect to susceptibility (i.e., highly susceptible) (Ehlenfeldt et al., 1996). Additional 
plants of 'Bluehaven' and 'Blueray' were added over time, as necessary, to maintain inoculum levels. To facilitate transfer of conidia from the blighted tissue to the stigmata, two hives of honeybees were placed in the netted cold frame, one at each end of the experimental area. To ensure that the resultant fruit developed only under the imposed conditions of the experiment, open flowers were removed from the test plants before setting the inoculum plants and bees in the cold frame. The experimental area was sprinkler-irrigated $(22 \mathrm{~mm} / \mathrm{d})$ every evening during conidia production. Fruit were picked while still green, $\approx 4$ to 6 weeks after flowering, and stored at $2{ }^{\circ} \mathrm{C}$ until evaluated. To evaluate for infection, each fruit was sliced in half crosswise and observed for the distinctive white fungal growth pattern of the mummy berry pathogen. For purposes of analysis, the incidence of mummy berry fruit infection was expressed as an uninfected proportion of berries. As with blight screening, cultivars were typically evaluated for 3 years, but sometimes longer if widely divergent results were observed within a cultivar.

\section{Statistical methods}

Minimum estimate for reliable resistance ratings. To determine the number of years of testing necessary to obtain reliable estimates of percent infection, we had data available from six standard cultivars present across either 11 or 12 years to assess mummy berry fruit infection (Table 2) and nine cultivars present across 8 years to assess shoot blight (Table 1). After preliminary evaluation, we suspected that there were insufficient years of data (especially for shoot blight) to determine exactly how many years were needed to produce a stable estimate for each cultivar, but believed there were sufficient years to provide a lower bound (minimum) for the number of years required. An intuitive way to do this is to determine when the estimated variance of the average disease incidence reaches its asymptotic value (or, equivalently, to determine how many years are necessary for this variance estimate to stop declining). Preliminary results suggested that this strategy would not be viable because the variance estimate was still declining at the maximum number of years for all cultivars.

As an alternative, we asked whether the estimated variance of disease resistance of varying subsets of years of data differed significantly from the variance calculated on the total set of available years conducted separately for each cultivar and based on results from resampling years of data. We also compared, for each subset of years, the variance of the estimated means (from the resampling) with the average model estimate of the variance of the mean. In other words, did the actual variance of the means, based on resampling, match what the models estimate this value to be? If they are not close, then the model estimate (typically published as a SE of the mean to convey the uncertainty in a dis- ease resistance estimate) is suspect because too few years of data are used.

For each standard cultivar data set, we resampled the data set 1000 times across different numbers of years beginning with the maximum available (total years -1 ) and decreasing to 2 years. We then fit a generalized linear mixed model to each subsampled subset, in which the dependent variables were the counts of uninfected and infected observations and the independent variables were a random year and a random year $\times$ plant interaction using the lmer function (lme4 package) from the $\mathrm{R}$ statistical computing software (R Development Core Team, 2007). The interaction term was added to account for any additional effects that might influence the estimate of the mean. We saved parameter estimates from each fit so that we could examine trends in the estimates as the number of years in the model decreased. As a measure of change, we calculated the mean square error (variance + bias squared) for the mean (the logit of the proportion of uninfected observations). The bias is the difference between the estimate for all years (the mean for all data for that cultivar) and the average estimate from models with 1 or more years of data dropped. To determine whether the variance estimate for total years differed significantly from model-based estimates from resampling, we asked "where in the distribution of model-based variance estimates from resampled data did the total years estimate lie?," i.e., was it in the bottom $5 \%$ or above this value? Recall that the average model-based variance estimate from resampled data sets was always greater than the total years estimate.

Weather variables. Several weather variables were evaluated as a likely source of yearto-year variation in infection incidence. Available weather data included: daily minimum-, maximum-, and mean- temperature, daily precipitation, and relative humidity (U.S. National Oceanic and Atmospheric Administration). Weather variables were assessed over the period of 1 Jan. to 30 May (ordinal Days 1 to 150 ). Growing degree days [average of the daily maximum and minimum temperatures compared with a $7.2{ }^{\circ} \mathrm{C}\left(45^{\circ} \mathrm{F}\right)$ base temperature] were calculated from these data and evaluated along with the weather variables.

Variables were grouped by 10 -d increments (i.e., mean maximum temperature for ordinal Days 1 to 10 , ordinal Days 11 to 20 , and so on) because this produced the best compromise between resolution and a meaningful average (i.e., gave the highest proportion of significant correlations). Five-d and 20 -d increments were also initially evaluated. For each of the cultivar standards, the correlation between the mean disease incidence (on both the logit and arcsine square root-transformed scales) and each of the weather variables for each $10-d$ increment was calculated. If at least two cultivar standards had significant correlations with the weather variable for that time period, we investigated the relationship further by looking at scatterplots of disease incidence versus weather variable to verify that the correlation was not the result of one or two outliers and that the relationship between the weather variable and other (nonsignificant) cultivars was not grossly different. This analysis provided us with a pool of candidate regressors. We then performed stepwise regression separately for each cultivar (evaluating both the logit and arcsine square root-transformed scales). The resulting model was inspected and occasionally reduced to remove borderline significant weather variables whose influence on $R^{2}$ was slight. The typical result was a model with one to three weather variables and an $R^{2}$ above 0.5 using data transformed with an arcsine square root variance stabilizing transformation. The $R^{2}$ value can be interpreted as the proportion of year-toyear variation that can be explained by the weather model.

Comparison of variance decomposition from cultivar and year. Variance decomposition was performed using the $R$ lmer function for the two disease phases using arcsine square root-transformed data and weighting by the square root of the sample size (to reduce the influence of small samples). The sources of variation in the model were cultivar, year, cultivar $\times$ year, and plant-to-plant variation + residual (sampling error and any other source of variation not previously accounted). For each cultivar, the part of the year-to-year variation attributable to the regression weather model is estimated by the weather model's $R^{2}$ value (see previous section).

Similarities between standards and cultivars with fewer years of data. Some cultivars with fewer years of data than the standards might have yearly patterns similar to one or more of the standards. For those with at least 3 years of data in common with one of the standards, we tested the correlation between the two. We accepted any cultivar as being similar to a standard in yearly pattern (although not necessarily similar in average disease incidence) if the correlation coefficient between the two was statistically significant $(P<0.05)$ and positive.

\section{Results}

Disease incidence in the standards. We first analyzed the fruit infection results because this data set had more years of data available. Preliminary line plots of fruit disease incidence over years for the standards were roughly parallel across some periods of years, but shifted ranks in others, indicating existence of a genotype-by-environment interaction (Fig. 1). To determine the number of years necessary to obtain reliable estimates of percent disease, we used the data for six cultivars over an 11- to 12-year period for assessing incidence of fruit infection. The analysis was conducted separately for each cultivar. We present the results for 'Atlantic' (ATL) and 'Northsky' (NOS) as examples (Fig. 2A-B).

For ATL, the 11-year estimate \{all estimates are on the logit scale; the logit scale is $\log [p /(1-p)]$, where $p$ is the estimate of 
disease incidence $\}$ of the variance of the mean is $\mathrm{y}=0.13$ (horizontal dotted line on graph). This is the model "population" estimate. The solid line gives the mean square error (MSE). The figure also shows the sum of the squared bias and the variance of estimates of the mean from resampling. The contribution of the squared bias is small. For each number of years resampled, we also plotted the average estimate of the variance of the mean from modeling (each time we resampled the data, we modeled it and estimated the variance of the mean, then averaged those estimates) referred to subsequently as model estimates. Note that the MSE from resampling for 4 or more years is smaller than the model estimates for partial years, as would be expected, because the former is based on resampling a "population" of 11 years, whereas the latter is attempting to estimate this parameter for an infinite population of years.

Several important results are shown in Figure 2A. The curve of the MSE does not flatten appreciably until $\approx 8$ years of data are available. With only 2 years of data, the variance of the mean (often reported as its square root, i.e., the SE of the mean) estimated by the model is considerably smaller than the estimate from resampling. Thus, with only 2 years of data, the SE of the mean from a model estimate would be misleadingly small, which would result in differences between cultivars being assigned far too liberally. This was also true for 3-year estimates for all standards, except ATL.

The average of the model estimates for partial years for ATL does not show any

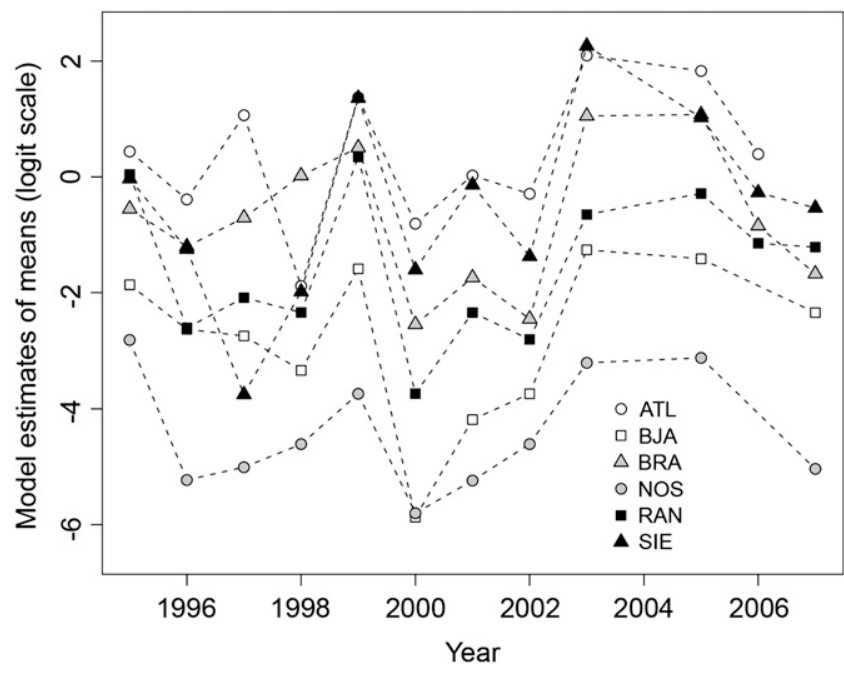

Fig. 1. Model estimates of fruit infection means (disease incidence, on logit scale) for six standard cultivars, 1995 to 2007. The standard cultivars included Atlantic (ATL), Bluejay (BJA), Blueray (BRA), Northsky (NOS), Rancocas (RAN), and Sierra (SIE).

indication that it has reached an asymptote at 10 years, so we assume an asymptote is still several years beyond this. At 8 to 10 years, the 11-year estimate was above the bottom $5 \%$ of the model estimates from resampling (data not shown). At 7 years, the 11-year estimate crossed into the bottom 5\% (data not shown), suggesting that 8 years is the minimum number of years that can be used for a reliable resistance estimate for this cultivar. For less than 7 years, the distribution of the model estimates of the variance from resampling widens such that the 11-year estimate is no longer found in the tail of the distribution.

The patterns for fruit infection in the remaining five standards were very similar to ATL, except for NOS, in which the resampling variances for 2 or 3 years of data were very large (Fig. 2B). For this cultivar, only the variance estimates from resampling are depicted for 2 and 3 years of data. The model estimates are not shown; they were so large as to be judged unreasonable (that is, anyone analyzing these data would reject those modeling results). This occurred because NOS is a resistant cultivar and there were many infection-free plants; on the logit scale, this value (one) gets pushed toward infinity, so variance estimates of the mean are inflated. For 'Blueray', the 12-year variance estimate crossed into the tail of the model estimates from resampling at 7 years (suggesting a minimum of 8 years is necessary). For 'Rancocas', the 12-year variance estimate crossed into the $5 \%$ tail at 5 years (but was below the $10 \%$ tail starting at 8 years). For the two other cultivars (Bluejay and Sierra), the distribution of the resampling variance estimates never became sufficiently narrow for the total years variance estimate to fall into the tail.

Results for blighting were similar (not shown) for the nine standards with 8 years of data. Overall, variances tended to be larger
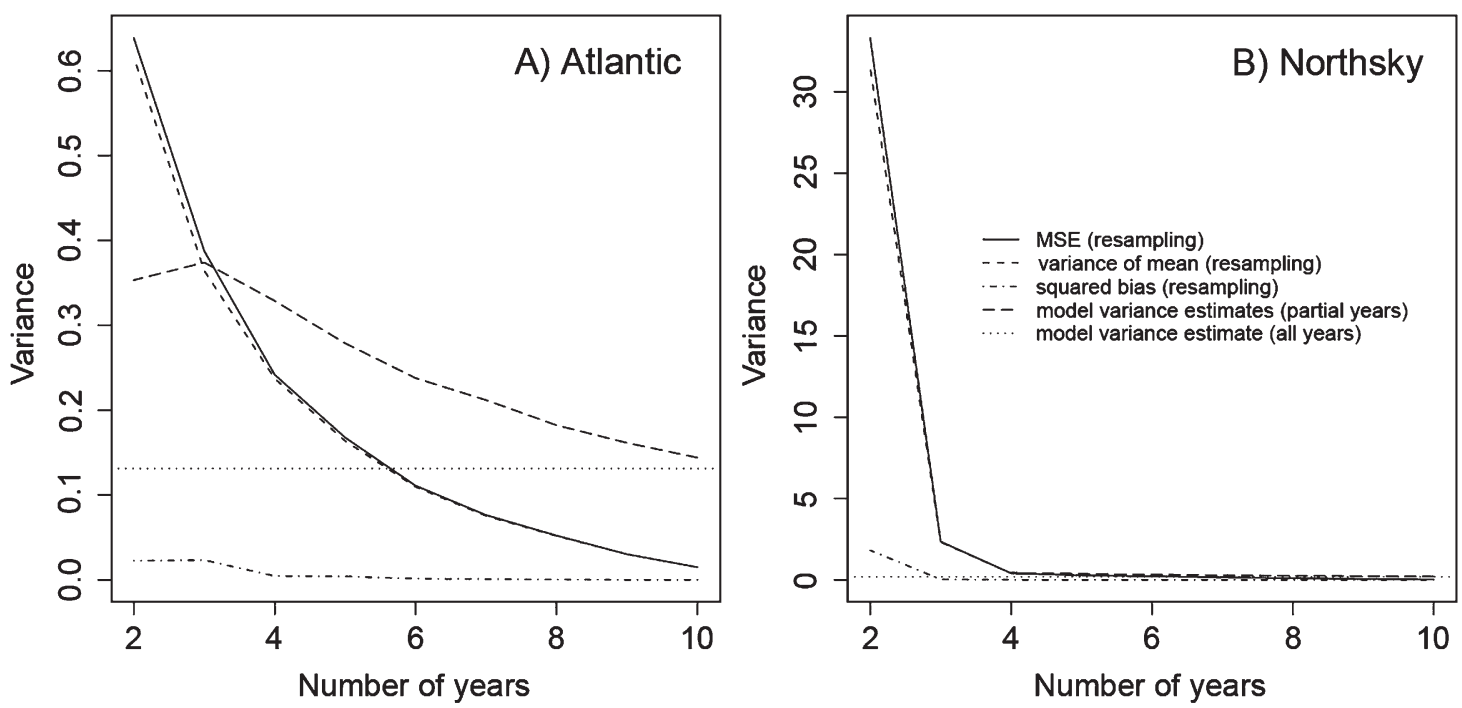

Fig. 2. Estimates of the variance of the mean, the mean square error (MSE), the sum of the squared bias, and the variance of estimates of the mean from resampling across 10 years for mummy berry disease incidence (on logit scale) in blueberry cultivars, (A) Atlantic and (B) Northsky. The mean estimate from modeling the variance of the mean is also included for each number of resampled years. Note the relative magnitude of the y-axis scale. Mean model variance estimates for 'Northsky' for 2 and 3 years are not depicted because they are so large. 
with the same gross underestimates of the model-based variance of the mean with only 2 years of data. The larger variances showed that resistance to shoot blight was more variable over years than was fruit infection. In only one cultivar, Sunrise, did the 8-year variance estimate fall into a $10 \%$ tail for 5 and fewer years (i.e., this would suggest that for 'Sunrise', 6 years of evaluation are sufficient to estimate a variance based on 8 years of data). The distributions of the resampling variance estimates were generally wider for these data than for the fruit disease incidence data, so statistical power was low.

Predictive weather variables. Weather variables were evaluated for possible correlations with disease incidence for both shoot blighting and fruit infection in each standard cultivar. We give results for these models in Tables 3 and 4, respectively. These models show that disease incidence in the spring can be well-predicted based on weather conditions from earlier that same year, although there are differences among the cultivar models.

For shoot blighting (Table 3), the most important predictors were precipitation weather variables, either rain frequency, $P_{f}$ (on ordinal Days 91 to 100, i.e., end of March), or average amount of precipitation, $\mathrm{P}_{\mathrm{avg}}$ (on ordinal Days 21 to 30, i.e., end of January) based on arcsine square root-transformed data. These models have high $R^{2}$ values ranging from 0.50 for 'Toro' to 0.95 for 'Baldwin' and 'Sunrise' and therefore should do a good job predicting average disease incidence. These values show a general trend of $R^{2}$ being higher for more susceptible cultivars, suggesting better predictability of disease incidence in such cultivars. For mummy berry fruit infection (Table 4), the common predictive variable for all models is the average maximum temperature across ordinal Days 51 to 60 (late February). For fruit infection, $R^{2}$ values had less predictive value than for shoot blight, ranging from 0.31 for 'Atlantic' to 0.76 for 'Blueray', and did not show any trend with disease incidence ranking.

Variance decomposition. The sources of variation in the model were cultivar (genotype), year (environment), cultivar $\times$ year (genotype $\times$ environment interaction), and plant-to-plant variation + residual (sampling error and any other source of variation not previously considered) (Table 5). For each cultivar, the year-to-year variation can be further decomposed into that part resulting from weather and that part resulting from other year-to-year effects, because the $R^{2}$ values in Tables 3 and 4 for each standard estimates the ratio of variation explained by the model (weather variables) to the total year-to-year variation.

The variance component estimates for the two disease phases were similar. The largest variance component was that resulting from the sum of plant-to-plant variation, sampling error, and other unknown sources. Although we did not separate the sampling error variance from other sources of variation for this

Table 3. Predictive equations for Monilinia vaccinii-corymbosi shoot blight incidence based on weather variables. $^{z}$

\begin{tabular}{llclr}
\hline Cultivar & \multicolumn{1}{c}{ Equation } & Adjusted $R^{2}$ & \multicolumn{1}{c}{$\mathrm{F}$ statistic } & \multicolumn{1}{c}{$P$} \\
\hline Baldwin (RE) & $\mathrm{y}=0.09+0.24 \mathrm{P}_{\mathrm{f}}+0.88 \mathrm{H}_{\min }$ & 0.95 & $\mathrm{~F}_{2,4}=56.20$ & 0.001 \\
Bluejay (HB) & $\mathrm{y}=0.33+1.65 \mathrm{P}_{\text {avg }}$ & 0.59 & $\mathrm{~F}_{1,4}=8.05$ & 0.047 \\
Brightwell (RE) & $\mathrm{y}=0.17+0.29 \mathrm{P}_{\mathrm{f}}$ & 0.86 & $\mathrm{~F}_{1,5}=37.09$ & 0.002 \\
Callaway (RE) & $\mathrm{y}=0.49+1.88 \mathrm{P}_{\text {avg }}$ & 0.58 & $\mathrm{~F}_{1,5}=9.26$ & 0.029 \\
Coastal (RE) & $\mathrm{y}=0.51+1.80 \mathrm{P}_{\text {avg }}$ & 0.72 & $\mathrm{~F}_{1,5}=16.69$ & 0.009 \\
Coville (HB) & $\mathrm{y}=0.10+0.28 \mathrm{P}_{\mathrm{f}}$ & 0.76 & $\mathrm{~F}_{1,6}=23.54$ & 0.003 \\
Northblue (HH) & $\mathrm{y}=0.91+1.03 \mathrm{H}_{\min }$ & 0.92 & $\mathrm{~F}_{1,5}=74.72$ & $<0.001$ \\
Sunrise (HB) & $\mathrm{y}=-0.17+0.18 \mathrm{P}_{\mathrm{f}}+2.72 \mathrm{H}_{\text {min }}$ & 0.95 & $\mathrm{~F}_{3,3}=44.55$ & 0.005 \\
& $-1.16 \mathrm{H}_{\text {avg }}$ & & & \\
Toro (HB) & $\mathrm{y}=0.08+0.21 \mathrm{P}_{\mathrm{f}}$ & 0.50 & $\mathrm{~F}_{1,6}=7.94$ & 0.030 \\
\hline
\end{tabular}

${ }^{2}$ The dependent variable is the arcsine square root-transformed proportion of infected stems. The independent variables are as follows: $P_{\mathrm{f}}=$ average rain frequency on ordinal Days 91 to $100, \mathrm{H}_{\min }=$ average minimum humidity on ordinal Days 1 to $10, \mathrm{P}_{\mathrm{avg}}=$ average amount of rain $(\mathrm{cm})$ on ordinal Days 21 to $30, \mathrm{H}_{\mathrm{avg}}=$ average of mean humidity on ordinal Days 41 to 50 .

${ }^{\mathrm{y}} \mathrm{RE}=$ rabbiteye; $\mathrm{HB}=$ highbush; $\mathrm{HH}=$ half-high.

Table 4. Predictive equations for Monilinia vaccinii-corymbosi fruit infection incidence based on weather variables. ${ }^{2}$

\begin{tabular}{|c|c|c|c|c|}
\hline Cultivar & Equation & Adjusted $R^{2}$ & F statistic & $P$ \\
\hline$\overline{\text { Atlantic }(\mathrm{HB})^{\mathrm{y}}}$ & $\mathrm{y}=0.85-0.24 \mathrm{~T}_{\max }$ & 0.31 & $F_{1,9}=5.50$ & 0.044 \\
\hline Bluejay (HB) & $\mathrm{y}=0.28-0.15 \mathrm{~T}_{\max }$ & 0.50 & $F_{1,9}=11.09$ & 0.009 \\
\hline Blueray (HB) & $\begin{aligned} \mathrm{y} & =1.01-1.00 \mathrm{~T}_{\max } \\
& +1.45 \mathrm{P}_{\mathrm{avg}}+0.83 \mathrm{GDD}_{\mathrm{avg}}\end{aligned}$ & 0.76 & $\mathrm{~F}_{3,8}=12.56$ & 0.002 \\
\hline Northsky $(\mathrm{HH})^{\mathrm{x}}$ & $\mathrm{y}=-4.56-1.53 \mathrm{~T}_{\max }$ & 0.51 & $\mathrm{~F}_{1,6}=8.24$ & 0.028 \\
\hline Rancocas (HB) & $\mathrm{y}=0.46-0.29 \mathrm{~T}_{\max }$ & 0.61 & $F_{1,10}=18.00$ & 0.002 \\
\hline Sierra $(\mathrm{HB})$ & $\mathrm{y}=0.69-0.42 \mathrm{~T}_{\max }$ & 0.70 & $F_{1,10}=26.14$ & $<0.001$ \\
\hline
\end{tabular}

${ }^{\mathrm{z}}$ Unless otherwise noted, the dependent variable is the arcsine square root-transformed proportion of infected berries. The independent variables are as follows: $\mathrm{T}_{\max }=$ average maximum air temperature on ordinal Days 51 to $60, \mathrm{P}_{\mathrm{avg}}=$ average amount of rain $(\mathrm{cm})$ on ordinal Days 51 to $60, \mathrm{GDD}_{\text {avg }}=$ average growing degree days, with $7.2^{\circ} \mathrm{C}\left(45^{\circ} \mathrm{F}\right)$ as the lower cutoff on ordinal Days 51 to 60 .

${ }^{\mathrm{y}} \mathrm{HH}=$ half-high; $\mathrm{HB}=$ highbush.

${ }^{\mathrm{x}}$ Logit transformed, i.e., $\mathrm{y}=\operatorname{logit}(p)$, where $p=$ disease incidence.

Table 5. Sources of variation of Monilinia vaccinii-corymbosi fruit infection and shoot blight evaluations.

\begin{tabular}{lcc}
\hline Source of variation & $\begin{array}{c}\text { Fruit infection variance } \\
\text { component and (percent) }\end{array}$ & $\begin{array}{c}\text { Shoot blight variance } \\
\text { component and (percent) }\end{array}$ \\
\hline Cultivar & $0.017(5.4)$ & $0.021(4.7)$ \\
Year & $0.037(11.5)$ & $0.048(10.8)$ \\
Cultivar $\times$ year & $0.075(23.3)$ & $0.126(28.2)$ \\
Individual plant + sampling error & $0.192(59.8)$ & $0.252(56.3)$ \\
Total & $0.321(100.0)$ & $0.447(100.0)$ \\
\hline
\end{tabular}

component, sampling error is readily calculated for each sample, because it depends only on $n$, the size of the sample (number of berries or shoots), and the parameter, $p$, estimating disease incidence. It is small when $n>100$ and is likely responsible for less than $10 \%$ of this variance component for these data, because $n$ was typically greater than 50 (on the arcsine transformation scale, sampling error variance is $\approx 0.005$ for $n=50$ with a disease incidence of $50 \%$ ). The cultivar main effect is relatively small and, for both phases of the disease, the cultivar $\times$ year interaction was larger than either of the two main effects (cultivar and year).

Ranking of standard cultivars for disease incidence. The standards, with many years of data, are ranked in Tables 1 and 2. Although these rankings are based on arcsine square root-transformed data, they are reported in the table as percentages. SES are slightly larger for shoot blight data, because they are based on fewer years than the fruit infection. Because there were only a few years of data on all other cultivars not used as standards, a ranking of them would not be stable. Cultivars with yearly patterns similar to one of the standards are given in Tables 1 and 2 .

\section{Discussion}

Our analysis of fruit disease incidence in the standard cultivars over 11 years indicated significant and large genotype-byenvironmental interactions. This means that rankings of resistance (fruit infection) are not stable from year to year and that the 2 or 3 years of data typically used for publication are insufficient to reliably estimate disease resistance. Because most cultivars are only tested for 2 to 3 years, this could lead to erroneous rankings depending on which years were sampled. There is a large body of literature on the stability of crop yield, both across locations and over years, and various definitions of stability (Lin and Binns, 1991), and our finding of a large cultivar-by-year interaction is not uncommon, although we measured disease incidence rather than yield. 
Our question differs from that commonly asked in yield stability literature, because we wanted to know how many years of data would be necessary to obtain a good measure of year-to-year variability rather than which cultivar tends to produce similar yields over various locations and years.

Our data show the curve of the MSE takes several years to begin flattening, and even with 11 years of data, the curves did not flatten completely (this was true for all standards). The results suggest that for cultivars that do not vary excessively from year to year (i.e., the distribution of the model variance estimates from resampling is not too wide), 8 years of data are necessary for a resistance estimate that is roughly as good as an 11- or 12-year estimate and that fewer years may produce unreliable estimates. This assumes that the 8 years are a fair representation of all the years sampled in the inference period. Our blight disease incidence results showed larger variances over similar time ranges; hence, it is likely that to reliably evaluate resistance, more years of data would be necessary than were used for fruit infection estimates.

Because accumulating 8 or more years of infection data on large numbers of cultivars is not generally feasible, we sought to determine if weather data before and during manifestation of the disease could be used to help predict disease incidence occurring that same year. We found the most important predictor of blight to be either average amount of precipitation at the end of January or rain frequency at the end of March. The most important predictor for fruit infection was found to be the average maximum temperature in late February.

We have shown that one or more weather variables can be statistically linked to disease incidence. Our models have high $R^{2}$ values, suggesting they should do a good job predicting average incidence of the disease, but it was unclear how these factors are actually linked to disease incidence. Weather variables in the context of our screenings (except perhaps temperature) were not directly causal. Our plants and mummies were in covered cold frames until early April so that precipitation could not have had a direct impact. However, precipitation often is accompanied by decreased light, increased humidity, and increased soil moisture, and any of these factors, not directly measured, could influence some aspect of plant or fungus physiology and the subsequent dis- ease incidence. Thus, the weather variables found useful in the modeling can be thought of as proxies for the true variables that affect infection.

For blighting, genetic effects among pseudosclerotia affect the infection process. Lehman and Oudemans (1997a) demonstrated mummy berry populations from localized areas were influenced by natural selection to adapt to better match the phenology of their host plant population. Similarly, fruit infection results from the interaction of many factors. Lehman et al. (2007) suggest differences in pollinator activity, attractiveness of cultivars to pollinators, and differences in cultivar phenology may all account for environmental differences between years.

Variance decomposition indicated that, for both phases of the disease, the cultivar $x$ year interaction was larger than either main effect. Thus, not only will overall disease incidence (or pressure) and cultivar response differ from year to year based on prevailing weather conditions and other factors, but they will not vary in a consistent manner.

Despite year-to-year variability, it is possible to group cultivars that respond similarly to the established standards with the idea that, by using the weather variable models derived for each standard cultivar, we might now be able to better understand the year-to-year responses of these "similar cultivars." Similarity of response does not imply similarity of resistance, but does imply that within the years used for the comparison, these cultivars ranked consistently above or below the standard with which they are grouped (i.e., had a similar cultivar $\times$ year interaction). Thus, by defining groups that share similar responses to environmental factors (e.g., possibly weather variables), we may be able to improve predictions of disease incidence for individual cultivars within these groups.

\section{Literature Cited}

Batra, L.R. 1983. Monilinia vaccinii-corymbosi (Sclerotiniaceae): Its biology on blueberry and comparison with related species. Mycologia $75: 131-152$

Batra, L.R. and S.W.T. Batra. 1985. Floral mimicry induced by mummy-berry fungus exploits host's pollinators as vectors. Science 228: 1011-1013.

Cox, K.D. and H. Scherm. 2001. Gradients of primary and secondary infection by Monilinia vaccinii-corymbosi from point sources of ascospores and conidia. Plant Dis. 85:955-959.

Eck, P. and N.F. Childers. 1966. Blueberry culture. Rutgers University Press, New Brunswick, NJ.
Ehlenfeldt, M.K. and A.W. Stretch. 2000. Mummy berry blight resistance in rabbiteye blueberry cultivars. HortScience 35:1326-1328.

Ehlenfeldt, M.K., A.W. Stretch, and V. Brewster. 1996. Genetic and morphological factors influence mummy berry blight resistance in highbush blueberry. HortScience 31:252-254.

Ehlenfeldt, M.K., A.W. Stretch, and J.S. Lehman. 1997. Shoot length affects susceptibility to mummy berry blight within highbush blueberry cultivars. HortScience 32:884-887.

Hildebrand, P.D., R.D. Milholland, and A.W Stretch. 1995. Mummy berry, p. 11-12. In: Caruso, F.L. and D.C. Ramsdell (eds.). Compendium of blueberry and cranberry diseases. American Phytopathological Society Press, St. Paul, MN

Lehman, J.S., S. Igarashi, and P.V. Oudemans. 2007. Host resistance to Monilinia vacciniicorymbosi in flowers and fruits of highbush blueberry. Plant Dis. 91:852-856.

Lehman, J.S. and P.V. Oudemans. 1997a. Phenology of apothecium production in populations of Monilinia vaccinii-corymbosi from early- and late-maturing blueberry cultivars. Phytopathology 87:218-223.

Lehman, J.S. and P.V. Oudemans. 1997b. Phenology of the mummy berry fungus and its blueberry host: Implications for resistance breeding. Acta Hort. 446:287-292.

Lin, C.S. and M.R. Binns. 1988. A method of analyzing cultivar $\times$ location $\times$ year experiments: A new stability parameter. Theor. Appl. Genet. 76:425-430.

Lin, C.S. and M.R. Binns. 1991. Genetic properties of four types of stability parameter. Theor. Appl. Genet. 82:505-509.

Nelson, J. and H.C. Bittenbender. 1971. Mummy berry disease occurrence in a blueberry selection test planting. Plant Dis. Rpt. 55:651-653.

Pepin, H.S. and H.N.W. Toms. 1969. Susceptibility of highbush blueberry varieties to Monilinia vaccinii-corymbosi. Phytopathology 59:18761878

R Development Core Team. 2007. A language and environment for statistical computing. R Foundation for Statistical Computing, Vienna, Austria. 2 Oct. 2007. <http://www.R-project.org>.

Stretch, A.W. and M.K. Ehlenfeldt. 2000. Resistance to the fruit infection phase of mummy berry disease in highbush blueberry cultivars. HortScience 35:1271-1273.

Stretch, A.W., M.K. Ehlenfeldt, and V. Brewster. 1995. Mummy berry blight resistance in highbush blueberry cultivars. HortScience 30:589591.

U.S. National Oceanic and Atmospheric Administration, National Climatic Data Center (cooperative station ID\# 283662, Hammonton, NJ). 1 Sept. 2009. <http://www.ncdc.noaa.gov/oa/ climate/stationlocator.html>.

Varney, E.H. and A.W. Stretch. 1966. Diseases and their control, p. 236-279. In: Eck, P. and N.F. Childers (eds.). Blueberry culture. Rutgers University Press, New Brunswick, NJ. 